\title{
Effect of Mn Doping on the Structural, Optical and Magnetic Properties of $\mathrm{SnO}_{2}$ Nanoparticles
}

\author{
M. Saravanakumar ${ }^{a, *}$, S. Agilan ${ }^{b}$, N. Muthukumarasamy ${ }^{b}$, V. Rukkumani $^{c}$, \\ A. Marusamy ${ }^{b}$ And A. Ranjitha ${ }^{b}$ \\ ${ }^{a}$ Department of Physics, SVS College of Engineering, Coimbatore, India \\ ${ }^{b}$ Department of Physics, Coimbatore Institute of Technology, Coimbatore, India \\ ${ }^{c}$ Department of Electronics and Instrumentation, Sri Ramakrishna Engineering College, Coimbatore, India
}

(Received March 4, 2014; in final form December 4, 2014)

Undoped and $\mathrm{Mn}$ doped $\mathrm{SnO}_{2}$ prepared by co-precipitation method exhibits nanocrystalline nature with prominent peaks along (110), (101), (211), and (310) planes. All the prepared samples are nanocrystalline with crystallite size lying in the range of $4.8-5.6 \mathrm{~nm}$. The prepared $\mathrm{SnO}_{2}$ nanoparticles exhibit single tetragonal crystalline phase. The high resolution transmission electron microscopy images show that the particles are nanocrystalline in nature. The composition of the prepared samples have been analyzed using energy dispersive analysis of X-rays spectra. The photoluminescence spectroscopy shows the recombination of electrons in singly occupied oxygen vacancies with photoexcited holes in the valence band. Broad UV emission at $426 \mathrm{~nm}$ is observed in photoluminescence. UV-vis absorption spectral studies showed a peak at $385 \mathrm{~nm}$. Magnetic measurements revealed that all the doped samples exhibit room temperature ferromagnetism, which is identified as an intrinsic characteristic obtained on doping. Pure $\mathrm{SnO}_{2}$ nanoparticles showed diamagnetism, $\mathrm{SnO}_{2}$ with lower $\mathrm{Mn}$ content show larger magnetization and with increasing $\mathrm{Mn}$ content the retentivity and coercivity are found to decrease.

DOI: $10.12693 /$ APhysPolA.127.1656

PACS: 75.60.Ej, 78.60.Lc, 61.46.Df, 68.37.Hk, 68.37.Og

\section{Introduction}

Tin oxide is a wide band gap $n$-type semiconductor and is one of the commonly used material for gas sensors, transparent conducting electrodes and optoelectronic devices operating at room temperature [1]. In recent years thin films of $\mathrm{SnO}_{2}$ have become an integral part of modern electronic technology. $\mathrm{SnO}_{2}$ transparent conducting oxide thin films are used as window layers and heat reflectors in solar cells [2]. Semiconductors with induced magnetization due to doping have an important role in spintronics.

The properties of impurity doped $\mathrm{SnO}_{2}$ nanoparticles are related to both composition and processing method. Nanocrystalline $\mathrm{SnO}_{2}$ and $\mathrm{Mn}$ doped $\mathrm{SnO}_{2}$ have been prepared by several methods such as co- precipitation [3], sol-gel [4-6], chemical vapour deposition [7, 8], VLS method [9], laser ablation [10] and thermal redox process [11]. Among these methods, chemical coprecipitation method is most effective due to its capability in controlling the structural and surface properties of nanoparticles. In the present study the structural, optical and magnetic properties of $\mathrm{SnO}_{2}$ and $\mathrm{Mn}$ doped $\mathrm{SnO}_{2}$ nanoparticles, prepared by chemical precipitation, method is reported.

High temperature ferromagnetism has been reported for Fe doped $\mathrm{SnO}_{2}$ [12], $\mathrm{Cr}$ doped $\mathrm{SnO}_{2}$ [13], V doped

${ }^{*}$ corresponding author; e-mail: saranspectra@gmail.com
$\mathrm{SnO}_{2}$ [14] and Ni doped $\mathrm{SnO}_{2}$ [15]. Mn doped $\mathrm{SnO}_{2}$ was found to be paramagnetic below the temperature of $5 \mathrm{~K}[16,17]$. Fitzgerald et al. [2] have discussed on the occurrence of ferromagnetism in terms of carrier mediated exchange in spin split impurities, band derived from bound magnetic polarons [18] or in a spin split $4 s / 5 s$ conduction band and then in terms of a model of ferromagnetic ordering of moments of molecular orbitals with $2 p$ hole character, which may be associated with defects in the interface region. It is therefore very significant to investigate ferromagnetism in doped and undoped semiconducting or insulating oxide powders, because only powders can reflect intrinsic magnetic properties of the material [20].

The optical properties of semiconductor nanoparticles have recently been a subject of great interest. Semiconductor nanoparticles have been explored as potential electroluminescent materials, with applications in optoelectronics [21]. One approach of producing strongly luminescent nanoparticles is to introduce small quantities of an emissive dopant. $\mathrm{SnO}_{2}$ nanoparticles have been successfully doped with $\mathrm{Mn}^{2+}$, and $\mathrm{Mn}^{2+}$ emission has been observed following band gap excitation. This emission has been assigned to the ${ }^{4} T_{1}-{ }^{6} A_{1}$ transition of the $\mathrm{Mn}^{2+}$ ion [5, 22], which is excited by energy transfer from the $\mathrm{ZnS}$ electron/hole state. However, with respect to nanocrystalline $\mathrm{SnO}_{2}$ semiconductor, to the best of our knowledge, there is no study on the luminescence characteristics of $\mathrm{Mn}^{2+}$ doped $\mathrm{SnO}_{2}$ nanoparticles. Doping influences the photoluminescence of $\mathrm{SnO}_{2}$ nanoparticles and calcination temperature also affects the luminescence 
process, which is due to the contribution of oxygen vacancies in the $\mathrm{SnO}_{2}$ host [5].

For $\mathrm{Mn}$ doped $\mathrm{SnO}_{2}$ nanoparticles, Tian et al. [23] have reported that magnetic properties strongly depend on both sintering temperature and doping content and no ferromagnetism was observed for samples sintered at a high temperature of $800^{\circ} \mathrm{C}$. Room temperature ferromagnetism (RTFM) with a saturation magnetic moment of $0.18 \mu_{\mathrm{B}} / \mathrm{Mn}$ ion was reported by Gopinadhan et al. [19] in Mn-doped $\mathrm{SnO}_{2}$ thin films. Recently, Fitzgerald et al. [2] have reported RTFM in pulsed laser deposited rutile $\mathrm{SnO}_{2}$ thin films with $\mathrm{Mn}$ doping. They observed a very large magnetic moment of $20 \mu_{\mathrm{B}} / \mathrm{Mn}$ ion at low doping concentration which is far above the spin magnetic moment of Mn. On the other hand, RTFM has been reported in undoped $\mathrm{SnO}_{2}$ nanoparticles [25], and thin films [26] containing no intentional magnetic elements as well as in other undoped wide band gap semiconductors and insulators [20-22].

\section{Experimental}

All chemicals used in the present work were of analytical grade and used without further purification. De-ionized water was used in all the synthesis steps. $\mathrm{SnO}_{2}$ nanoparticles doped with three different concentration of $\mathrm{Mn}, 2 \%, 4 \%$, and $6 \%$, were prepared by chemical co-precipitation method. The precursors for dopant and host were manganese acetate tetra hydrate $\left(\left(\mathrm{CH}_{3} \mathrm{COO}\right)_{2} \mathrm{Mn} \cdot 4 \mathrm{H}_{2} \mathrm{O}\right)$ and tin chloride $\left(\mathrm{SnCl}_{2} \cdot 2 \mathrm{H}_{2} \mathrm{O}\right)$, respectively. The solution was prepared using tin chloride $\left(\mathrm{SnCl}_{2} \cdot 2 \mathrm{H}_{2} \mathrm{O}\right)$ and manganese acetate tetra hydrate $\left.\left(\left(\mathrm{CH}_{3} \mathrm{COO}\right)_{2} \mathrm{Mn} \cdot 4 \mathrm{H}_{2} \mathrm{O}\right)\right)$ in distilled water to make $0.3 \mathrm{M}$ solution and aqueous ammonia $\left(\mathrm{NH}_{3} \mathrm{OH}\right)$ of $0.4 \mathrm{M}$ was added with the solution to increase the $\mathrm{pH}$ of the solution for the precipitate formation. The source materials were weighed according to the stoichiometry as per the target compositions and were dissolved in distilled water to make 0.3 M solution. Aqueous solution of ammonia was added dropwise to the solution of tin chloride precursor under continuous stirring for $3 \mathrm{~h}$ at room temperature till fine precipitate was formed. Using the same method, we have repeated the procedure for various concentration of $\mathrm{SnCl}_{2} \cdot 2 \mathrm{H}_{2} \mathrm{O}$ for molar values of 0.4 and $0.5 \mathrm{M}$, respectively. The solution obtained was centrifuged at $3000 \mathrm{rpm}$ for $10 \mathrm{~min}$. The precipitate was filtered out separately and washed with de-ionized water to remove the unnecessary impurities formed during the precipitation process. The obtained product was placed in oven for $8 \mathrm{~h}$ at $60^{\circ} \mathrm{C}$.

X-ray diffraction (XRD) studies have been carried out using PANalytical X-ray diffractometer. Elemental composition of the prepared samples has been studied using energy dispersive analysis of X-rays (EDAX, Thermo-Noran system Six). The high resolution transmission electron microscope (HRTEM) images of the prepared $\mathrm{SnO}_{2}$ nanoparticles have been recorded using JEOL JEM 2010 microscope. The optical properties have been studied using absorbance spectrum recorded using spectrophotometer (JASCO V-570). Photoluminescence emission spectrum has been recorded using Cary Eclipse spectrophotometer.

\section{Results and discussion \\ 3.1. Structural studies}

Figure 1 shows the powder XRD pattern of $\mathrm{SnO}_{2}$ and Mn-doped $\mathrm{SnO}_{2}$ nanoparticles. All the diffraction peaks are well assigned to the rutile type tetragonal system of $\mathrm{SnO}_{2}$ nanoparticles (JCPDS No. 88-0287). The diffraction peaks are observed to shift towards higher angles with increase in Mn content which indicates that Mn ion has substituted for Sn without changing the rutile structure. This is consistent with the reported solubility limit in nanoparticles [30], and powders [31] of $\mathrm{Mn}$ in $\mathrm{SnO}_{2}$. The observation of peak broadening is due to the presence of smaller crystallite size. The crystallite sizes were estimated using the Scherrer relation [29]:

$$
D=\frac{K \lambda}{\beta \cos \theta},
$$

where $D$ is the grain size, $K$ is a constant taken to be $0.94, \lambda$ is the wavelength of the $\mathrm{X}$-ray radiation, $\beta$ is the full width at half maximum and $\theta$ is the angle of diffraction. The crystallite size of $\mathrm{SnO}_{2}$ and $\mathrm{Mn}$ doped $\mathrm{SnO}_{2}$ are found to lie in the range $4.8-5.6 \mathrm{~nm}( \pm 0.1 \mathrm{~nm})$.

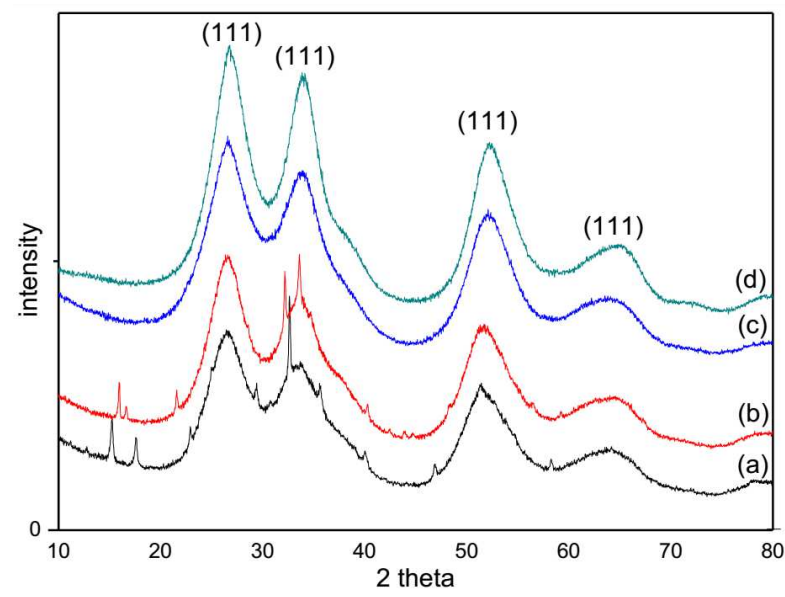

Fig. 1. XRD Pattern of (a) pure $\mathrm{SnO}_{2}$, (b) $2 \% \mathrm{Mn}$ Doped $\mathrm{SnO}_{2}$, (c) $4 \% \mathrm{Mn}$ Doped $\mathrm{SnO}_{2}$, (d) $6 \% \mathrm{Mn}$ Doped $\mathrm{SnO}_{2}$.

A small reduction in crystallite size is observed with increase of Mn concentration. The reduction of the crystallite size suggests that the $\mathrm{Mn}$ ion replaces the $\mathrm{Sn}$ ion. The presence of Mn ions in the crystallographic structure increases the formation of oxygen vacancies as required by the charge balance. The properties of nanomaterials are related to the particle size. To explain the possibility of nanomaterials as potential candidates for different applications it is necessary to have an accurate knowledge of the mean particle size and the size distribution. It is the dopant ions that contribute to the change of structure and light absorption efficiency of the host material. A 


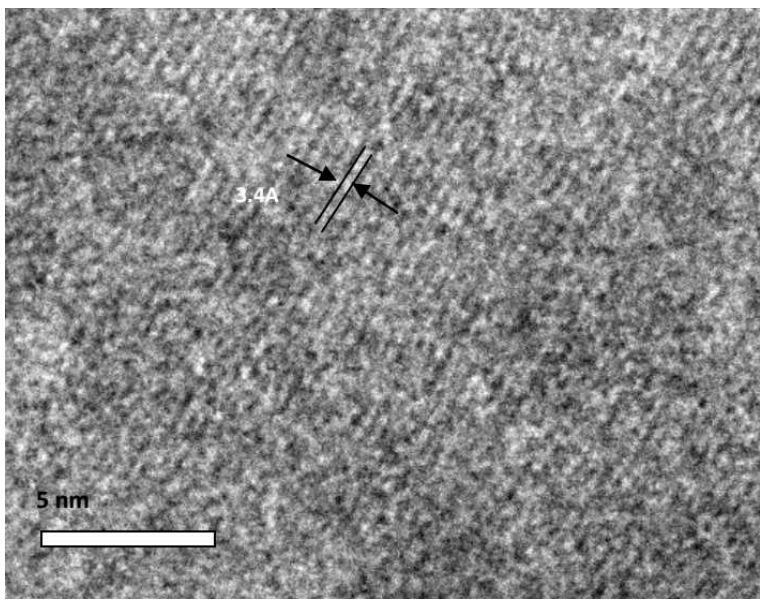

Fig. 2. HR-TEM images of the $\mathrm{SnO}_{2}$ nanoparticles.

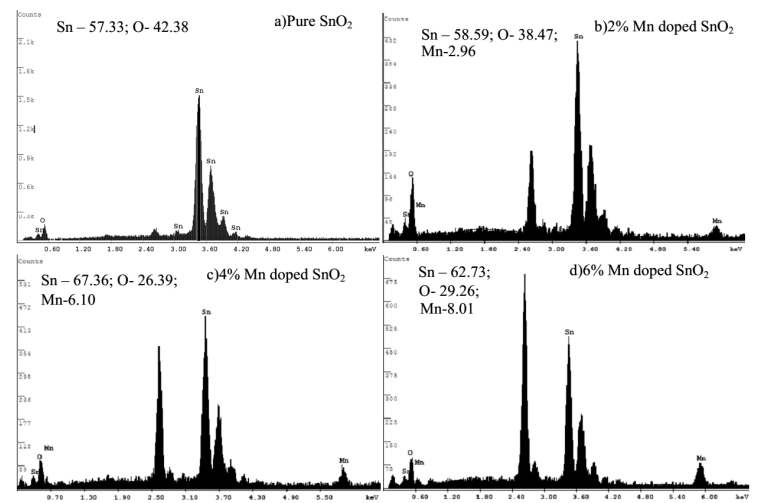

Fig. 3. EDAX Spectra of (a) pure $\mathrm{SnO}_{2}$, (b) $2 \%$ $\mathrm{Mn}$ doped $\mathrm{SnO}_{2}$.

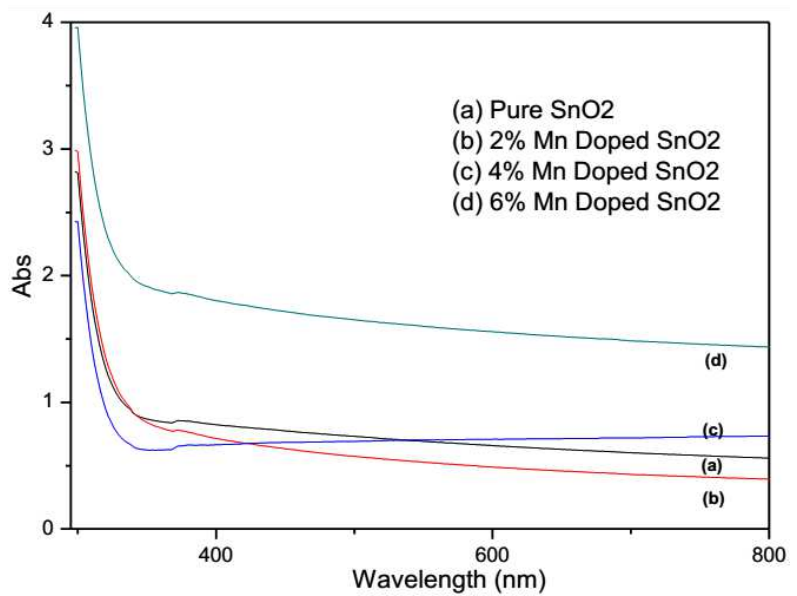

Fig. 4. Absorption spectra of (a) pure $\mathrm{SnO}_{2}$ (b) $2 \%$ $\mathrm{Mn}$ doped $\mathrm{SnO}_{2}$, (c) $4 \% \mathrm{Mn}$ doped $\mathrm{SnO}_{2}$, (d) $6 \%$ $\mathrm{Mn}$ doped $\mathrm{SnO}_{2}$.

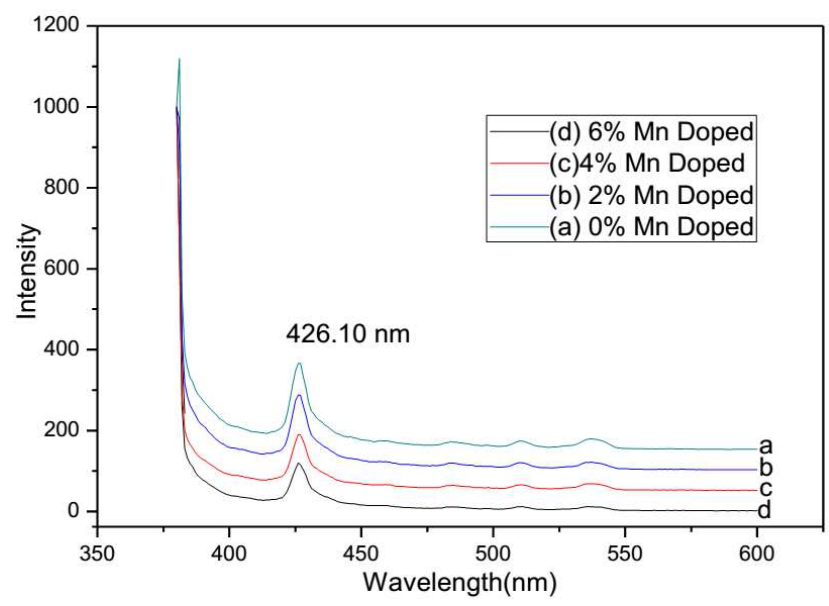

Fig. 5. Emission spectra of (a) pure $\mathrm{SnO}_{2}$, (b) $2 \%$ $\mathrm{Mn}$ doped $\mathrm{SnO}_{2}$, (c) $4 \% \mathrm{Mn}$ doped $\mathrm{SnO}_{2}$, (d) $6 \%$ $\mathrm{Mn}$ doped $\mathrm{SnO}_{2}$.

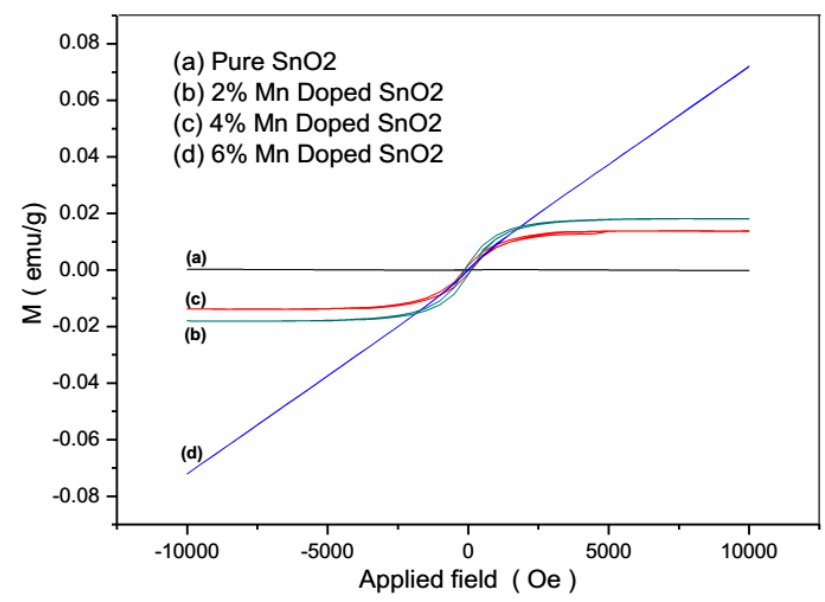

Fig. 6. Magnetisation curve of (a) pure $\mathrm{SnO}_{2}$, (b) $2 \%$ Mn doped $\mathrm{SnO}_{2}$, (c) $4 \% \mathrm{Mn}$ doped $\mathrm{SnO}_{2}$, (d) $6 \%$ $\mathrm{Mn}$ doped $\mathrm{SnO}_{2}$.

part of these ions are incorporated in substitutional or interstitial sites of $\mathrm{SnO}_{2}$. This is because when an element is being doped into a matrix, it can either "substitute" or "interstice". The dopant will occupy the interstitial sites at least to some extent and distort the crystal lattice structure. Hence a difference in crystallite size was observed. This effect in conjunction with the smaller ionic radius of $\mathrm{Mn}^{2+}$ ion in comparison to $\mathrm{Sn}^{4+}$ ion can disturb long range crystallographic ordering, thus reducing the crystallite size. From the diffraction pattern, it is observed that there is no impurity phase such as manganese oxide or other tin oxides present in the sample.

HRTEM images shown in Fig. 2a,b exhibit lattice fringes and lattice spacing has been calculated using these fringes. Interplanar spacing of $\mathrm{SnO}_{2}$ nanoparticle is $d=$ $3.5 \AA$ which corresponds to (110) plane of the rutile tetragonal phase and the tetragonal lattice has quadru- 
plicate symmetry. Oxygen atoms (anions) form octahedral and half of the octahedral interstices are filled by $\mathrm{Sn}$ atoms [18].

Figure 3 shows the EDAX spectra, collected from the average scanned area, of pure $\mathrm{SnO}_{2}$, and $\mathrm{Mn}$ doped $(2 \%$, $4 \%$ and $6 \%) \mathrm{SnO}_{2}$ samples, respectively. It shows that $\mathrm{Sn}$ and $\mathrm{O}$ are the only main elemental species in pure $\mathrm{SnO}_{2}$ sample while, additionally, $\mathrm{Mn}$ peaks are observed in Mn doped samples.

\subsection{Optical studies}

Nanosized semiconductor particles generally exhibit a threshold energy in the optical absorption measurements, due to the size-specific band gap structures [33-35], which is reflected by the blue shift of the absorption edge with decrease of particle size. The optical absorption spectra of the $\mathrm{SnO}_{2}$ sample and samples with three different $\mathrm{Mn}$ concentrations $(2 \%, 4 \%$, and $6 \%)$ are shown in Fig. 4. Pure $\mathrm{SnO}_{2}$ and $\mathrm{Mn}$ doped $\mathrm{SnO}_{2}$ absorption peak located at $386.79 \mathrm{~nm}$ is shifted relative to the bulk excitation absorption $(367.15 \mathrm{~nm})$. This shift indicates the quantum confinement property of nanoparticles. In the quantum confinement range, considering the absorption positions from the bulk $\mathrm{SnO}_{2}$, the absorption on sets of the present samples can be assigned to the direct transition of electron in the $\mathrm{SnO}_{2}$ nanocrystals. One of the main objectives of the present investigation is to study the effect of $\mathrm{Mn}^{2+}$ ions on the luminescence properties of the $\mathrm{SnO}_{2}$ host.

Figure 5 shows the emission spectra of $\mathrm{SnO}_{2}$ and $\mathrm{Mn}$ doped $\mathrm{SnO}_{2}$ with concentration $(2 \%, 4 \%$, and $6 \%)$. The emission spectra shows one strong band at $420 \mathrm{~nm}$. From Fig. 5, it can be observed that the addition of $\mathrm{Mn}^{2+}$ to $\mathrm{SnO}_{2}$ host lattice can result in the decrease of photoluminescence (PL) intensity of $\mathrm{SnO}_{2}$ host, while the characteristic peaks of $\mathrm{Mn}^{2+}$ ions could not be collected, which differs from the behavior of $\mathrm{Mn}^{2+}$ in $\mathrm{SnO}_{2}$ host. In pure $\mathrm{SnO}_{2}$ host, the emission attributes to electron transition, mediated by defects levels in the band gap, such as oxygen vacancies, tin interstitials and so forth. Probably after introducing $\mathrm{Mn}^{2+}$ into the $\mathrm{SnO}_{2}$ host, the defects still play a dominant role with respect to the luminescence processes.

Generally, oxygen vacancies are known to be the most common defects and usually act as radiative centers in luminescence processes. The oxygen vacancies are present in three different charge states: $V_{o}^{0}, V_{o}^{+}, V_{o}^{2+}[36]$ in the oxide. As $V_{o}^{0}$ is a very shallow donor, the most oxygen vacancies will be in their paramagnetic $V_{o}^{+}$state under flat-band conditions. The origin of luminescence is assigned to the recombination of electrons in singly occupied oxygen vacancies with photoexcited holes in the valence band. The luminescence spectra of the nanoscaled pure $\mathrm{SnO}_{2}$ powder is similar to those from nanocrystals of $\mathrm{TiO}_{2}, \mathrm{ZnO}$, and $\mathrm{BaTiO}_{3}$ [37-39]. After the addition of $\mathrm{Mn}^{2+}$ to the host lattice, it is easy for $\mathrm{Mn}^{2+}$ ion to substitute for $\mathrm{Sn}^{4+}$ ion, which can be due to the fact that the radius of $\mathrm{Sn}^{4+}(0.76 \AA)$ is similar to that of
$\mathrm{Mn}^{2+}(0.80 \AA)$ ion [40]. In addition, the 2 - charge of the $M n_{S n}^{2-}$ ion has to be compensated for somewhere in the lattice in the form of oxygen vacancy. That is the reason why the PL intensity rose rapidly and reached a maximum. At higher $\mathrm{Mn}^{2+}$ concentrations, the intensity of the $400 \mathrm{~nm}$ peak started to decrease slowly. Similar quenching effect with the $\mathrm{Mn}^{2+}$ concentration has been reported previously. Although the exact mechanism for this quenching to occur is still a matter of controversy, it is generally considered that the quenching of the luminescence is associated with interaction among $\mathrm{Mn}^{2+}$ ions with the nearest, the second nearest, and probably even the third nearest neighbor sites [41], forming small clusters, such as pairs or triplets, located on the surface or on the grain boundaries of the nanopowders.

\subsection{Magnetic studies}

The magnetic measurements $(M-H)$ of samples at room temperature have been carried out in the field range of 0-20 kOe. Figure 6 shows the $M-H$ curves of undoped and $\mathrm{Mn}$ doped $\mathrm{SnO}_{2}$ nanoparticles. Although undoped $\mathrm{SnO}_{2}$ nanoparticles are showing diamagnetism, incorporation of $\mathrm{Mn}$ into $\mathrm{SnO}_{2}$ shows ferromagnetism. The ferromagnetism may be due to the substitution of $\mathrm{Mn}$ into $\mathrm{SnO}_{2}$ lattice or due to the presence of secondary oxide phases of Mn [5]. But in the presence study no oxide phases have been formed according to the XRD results, the observed ferromagnetism is due to $\mathrm{Mn}$ doping out of all oxides of $\mathrm{Mn}\left(\mathrm{MnO}, \mathrm{Mn}_{2} \mathrm{O}_{3}, \mathrm{Mn}_{3} \mathrm{O}_{4}\right)$ only $\mathrm{Mn}_{3} \mathrm{O}_{4}$ is ferrimagnetic with a Curie temperature $\left(T_{\mathrm{C}}\right)$ of $42 \mathrm{~K}[5,42,43]$. Since the $T_{\mathrm{c}}$ is too low, the observed room temperature ferromagnetic behavior in the samples cannot be attributed to the $\mathrm{Mn}_{3} \mathrm{O}_{4}$ phase.

From Fig. 6 it is observed that pure $\mathrm{SnO}_{2}$ nanoparticles exhibit diamagnetism, $\mathrm{SnO}_{2}$ with lower $\mathrm{Mn}$ content (2\%) showed larger magnetization and with increasing Mn content $(4 \%, 6 \%)$, the ferromagnetization decreases. The retentivity and coercivity of all samples are calculated and are shown in Table II.

When Mn doping is $2 \%$, most of the $\mathrm{Mn}^{2+}$ ions occupy substitutional position. $\mathrm{Mn}^{2+}$ ions, on substitution, create oxygen vacancies (as inferred from the appearance of visible emission peaks), those oxygen vacancies alone cannot to contribute to ferromagnetism. Increase of Mn increases the number of oxygen vacancies and therefore an exchange interaction of the $\mathrm{Mn}$ ions via oxygen vacancies may induce ferromagnetism. Although oxygen vacancies can be expected to be more at $4 \%$ and $6 \%$, the interaction of $\mathrm{Mn}^{2+}$ via oxygen vacancies is less pronounced. Therefore, both oxygen vacancies and an optimum level of $\mathrm{Mn}$ (with entire $\mathrm{Mn}^{2+}$ taking part in BMP) are necessary for obtaining ferromagnetism in $\mathrm{Mn}$ doped $\mathrm{SnO}_{2}$ nanoparticles. High concentration of Mn contributes only to paramagnetism.

\section{Conclusion}

$\mathrm{SnO}_{2}$ and $\mathrm{Mn}$ doped $\mathrm{SnO}_{2}$ nanoparticles have been successfully prepared by Co-precipitation method. From 
$\mathrm{X}$-ray diffraction studies, it is observed that the synthesized $\mathrm{SnO}_{2}$ nanoparticles are of rutile tetragonal phase and the crystallite size is in the range of 4.8 to $5.6 \mathrm{~nm}$. The studies also indicate that the grain size decreases with increase in Mn content. The HRTEM images exhibited lattice fringes which corresponds to the (110) plane of rutile tetragonal phase. The PL spectra consisted of a strong UV peak and a broad blue green peak. Strong band observed at $426 \mathrm{~nm}$ in PL spectra is due to the recombination of electrons in singly occupied oxygen vacancies with photoexcited holes in valence band. A systematic change in magnetic behavior from diamagnetic to ferromagnetic was observed and the samples exihibited ferromagnetic behavior for the Mn doping of $x=0.025$ to $x=0.075$ has been observed. Thus Mn concentration plays an important role in inducing ferromagnetism in nanocrystalline $\mathrm{Sn}_{1-x} \mathrm{Mn}_{x} \mathrm{O}_{2}$.

\section{References}

[1] G. Ansari, P. Boroojerdian, S.R. Sainkar, R.N. Karekar, R.C. Aiyer, S.K. Kulkarni, Thin Solid Films 295, 271 (1997).

[2] C.B. Fitzgerald, M. Venkatesan, L.S. Dorneles, R. Gunning, P. Stamenov, J.M.D. Coey, Phys. Rev. B 74, 115307 (2006).

[3] M.N. Rumyantseva, V.V. Kovalenko, A.M. Gaskov, T. Pagnier, D. Machon, J. Arbiol, J.B. Morante, Sens. Actuat. B Chem 109, 64 (2005).

[4] L. Broussous, C.V. Santilli, S.H. Pulcinelli, A.F. Craievich, J. Phys. Chem. B 106, 2855 (2002).

[5] F. Gu, S.F. Wang, M.K. Lu, Y.X. Qi, G.J. Zhou, D. Xu, D.R. Yuan, Inorg. Chem. Commun. 6, 882 (2003).

[6] D. Kotsikau, M. Ivanovskaya, D. Orlik, M. Falasconi, Sens. Actuat. B Chem. 101, 199 (2004).

[7] S. Suh, Z. Zhang, W. Chu, D.M. Hoffman, Thin Solid Films 345, 240 (1999).

[8] M. Huh, S. Kim, J. Ahn, J. Park, B. Kim, Nanostruct. Mater. 11, 211 (1999).

[9] J.H. He, T.H. Wu, C.L. Hsin, K.M. Li, L.J. Chen, Y.L. Chueh, L.J. Chou, Z.L. Wang, Small 2, 116 (2006).

[10] G. Williams, G.S.V. Coles, Mater. Res. Soc. Bull. 24, 25 (1999).

[11] O.A. Fouad, Cryst. Res. Technol. 41, 880 (2006).

[12] S.B. Ogale, R.J. Choudhary, J.P. Buban, S.E. Lofland, S.R. Shinde, S.N. Kale, V.N. Kulkarni, J. Higgins, C. Lanci, J.R. Simpson, N.D. Browning, S. Das Sarma, H.D. Drew, R.L. Greene, T. Venkatesan, Phys. Rev. Lett. 91, 077205 (2003).

[13] J.M.D. Coey, A.P. Douvalis, C.B. Fitzgerald, M. Venkatesan, Appl. Phys. Lett. 84, 1332 (2004).

[14] N.H. Hong, J. Sakai, W. Prellier, A. Hassini, J. Phys. Condens. Matter 17, 1697 (2005).

[15] N.H. Hong, J. Sakai, Physica B 358, 265 (2005).

[16] N.H. Hong, J. Sakai, N.T. Huong, N. Poirot, A. Ruyter, Phys. Rev. B 72, 045336 (2005).
[17] N.H. Hong, A. Ruyter, W. Prellier, J. Sakai, N.T. Huong, J. Phys. Condens. Matter 17, 6533 (2005).

[18] T. Kasuya, Solid State Commun. 8, 1635 (1970).

[19] K. Gopinadhan, S.C. Kashyap, D.K. Pandya, S. Chaudhary, J. Appl. Phys. 102, 113513 (2007).

[20] V.L. Colvin, M.C. Schlamp, A.P. Alivistos, Nature 370, 354 (1994).

[21] R.N. Bhargava, D. Gallagher, T. Welker, J. Lumin 60, 275 (1994).

[22] R.N. Bhargava, D. Gallagher, X. Ilong, A. Nurmikko, Phys. Rev. Lett. 72, 416 (1994).

[23] Z.M. Tian, S.L. Yuan,J.H. He, P. Li, S.Q. Zhang, C.H. Wang, Y.Q. Wang, S.Y. Yin, L. Liu, J. Alloys Comp. 466, 26 (2008).

[24] A. Sundaresan, R. Bhargavi, N. Rangarajan, U. Siddesh, C.N.R. Rao, Phys. Rev. B 74, 161306(R) (2006).

[25] N.H. Hong, N. Poirot, J. Sakai, Phys. Rev. B 77, 33205 (2008).

[26] J.M.D. Coey, M. Venkatesan, P. Stamenov, C.B. Fitzgerald, L.S. Dorneles, Phys. Rev. B 72, 24450 (2005).

[27] A. Sundaresan, C.N.R. Rao, Solid State Commun. 149, 1197 (2009)

[28] C. Madhu, A. Sundaresan, C.N.R. Rao, Phys. Rev. B 77, 201306(R) (2008).

[29] N.S. Sabri, A.K. Yahya, M.K. Talari, AIP Conf. Proc. 1250, 436 (2010).

[30] C. Van Komen, A. Thurber, K.M. Reddy, J. Hays, A. Punnoose, J. Appl. Phys. 103, 7D141 (2008).

[31] L.B. Duan, G.H. Rao, J. Yu, Y.C. Wang, G.Y. Liu, J.K. Liang, J. Appl. Phys. 101, 63917 (2007).

[32] A. Sharma, M. Varshney, S. Kumar, K.D. Verma, R. Kumar, Nanomater. Nanotechnol. 1, 24 (2011).

[33] A. Henglein, Chem. Rev. 89, 1861 (1989).

[34] Y. Wang, N. Herron, J. Phys. Chem. 95, 525 (1991).

[35] H. Weller, Adv. Mater. 5, 88 (1993).

[36] K. Vanheusden, W.L. Warren, C.H. Seager, D.R. Tallant, J.A. Voigt, B.E. Gnade, J. Appl. Phys. 79, 7983 (1996).

[37] W.F. Zhang, M.S. Zhang, Z. Yin, Q. Chen, Appl. Phys. B 70, 261 (2000).

[38] W.F. Zhang, M.S. Zhang, Z. Yin, Phys. Status Solidi A 179, 319 (2000).

[39] D.W. Bahnemann, C. Kormann, M.R. Hoffmann, J. Phys. Chem. 91, 3789 (1987).

[40] B. Choudhury, A. Choudhury, Curr. Appl. Phys. 13, 1025 (2013).

[41] C. Falcony, M. Garcia, A. Ortiz, J.C. Aloaso, J. Appl. Phys. 72, 1525 (1992).

[42] S. Sharma, S. Chaudhary, S.C. Kashyap, V.K. Malik, J. Alloys Comp. 509, 7434 (2011).

[43] Z.M. Tian, S.L. Yuan, Y.Q. Wang, J.H. He, S.Y. Yin, K.L. Liu, S.J. Yuan, L. Liu, J. Phys. D Appl. Phys. 41, 055006 (2008).

[44] S. Sharma, S. Chaudhary, S.C. Kashyap, S.K. Sharma, J. Appl. Phys. 109, 083905 (2011). 